\title{
Genes and discrimination
}

No one talks about the sense of excitement and hope that accompanies the steady progress in human genetics without mentioning in the same breath the notion than molecular genetics poses unique ethical issues. Medicine's ability to identify in healthy people genes that may predispose them to future disease is often regarded as one of the most perplexing "ethical" questions. Will employers and insurance companies discriminate against people known to carry a gene associated with cancer, or neurodegenerative disease, or heart failure?

The answer, regrettably, is yes. Although data on the full scope of genetic discrimination are slight, there is no doubt that it happens. People have been denied employment because a relative has Huntington's disease, for instance. And there is evidence that people have refused potentially valuable genetic screening for fear of discrimination should they have a gene that predisposes them to cancer, or cystic fibrosis, or heart disease.

Insurance companies routinely deny coverage to people with "pre-existing conditions"; employers prefer not to hire people who are likely to run up large medical bills. Insur-

$C P$ 's genetic profile reveals an increased susceptibility to colon cancer. CP is currently asymptomatic and may never in fact develop colon cancer. After making $C P$ a conditional offer of employment, $R$ [employer] learns about $C P$ 's increased susceptibility to colon cancer. $R$ then withdraws the job offer because of concerns about matters such as CP's productivity, insurance costs, and attendance. * ance companies after all are businesses, not public charities. It is no surprise that they discriminate against the sick or potentially sick whenever possible. This being so, medicine's ability to identify increasing numbers of disease genes has, among its adverse side effects, the fact that genetic information can be bad for chances of getting employment or insurance.

But the solution to what is posed as a complex ethical issue lies not in the realm of ethical analysis but in the practical world of law and public policy. And on $14 \mathrm{March}$, in the United States, an agency with the authority to affect the real world issued a decision that is good for people and good for the future of genetic research. The US Equal Employment Opportunities Commission declared that under the Americans with Disabilities Act (1990), a genetic susceptibility to disease is a protected disability within the meaning of the law. The example given is marvelously clear. It should give heart to people who otherwise fear genetic test-

*The EEOC's example of prohibited discrimination based on a person's status as the carrier of a disease-realted gene. ing, encourage scientists to push ahead with research, and give fair warning to employers and insurers that their licence to discriminate may soon expire.

According to the EEOC's interpretation of the disabilities law, $\mathrm{R}$ is in deep trouble, vulnerable to a legal suit for genetic discrimination. (In fact, $\mathrm{R}$ would be vulnerable under the Americans with Disabilities Act even if CP actually did have colon cancer.)

The EEOC's decision to define a person's genetic status as a disability under certain conditions is an important first step in eliminating the inherently distasteful practice of allowing insurance companies to selectively insure the healthy among us and screen out the rest. Although insurance companies are not bound by the disabilities act, employers are. One does not have to stretch the imagination to assume that employers, who have considerable power in negotiating health care policies for their workers, will negotiate policies that include coverage without regard to a person's genetic profile.

It is morally the right thing to do. Equally important, it is also the only practical thing to do. In light of the extraordinary advances in human genetics, it will not be long before it is possible to show that nearly every single one of us carries one or another disease gene. True, there is much research still to be done before we can effectively treat the diseases we can now link to certain genes, but the trend is unambiguous and the scope of gene-related diseases is vast.

Two examples were reported in the April issue of Nature Medicine. Alcoholics may have a mutation in the receptor genes for serotonin that influences addiction. Individuals who survive a decade or more after infection by the AIDS virus may carry a protective mutation in the receptors of their $\mathrm{CD}^{+}$immune cells. Significant progress in understanding the genetics of non-insulin-dependent diabetes (which afflicts 5 per cent of the world's population) was reported in the March issue of Nature Genetics. The list of diseases with a known genetic component would fill pages. Beyond doubt the range of genetic permutations in the human population is so vast (and so susceptible to medical understanding) that it is silly to assume any (or many) of us are born with a perfect genetic profile. It would be tragic if genetic discrimination in the workplace or insurance market were to deter people from participating in clinical studies or cause scientists to shy away from this vital research.

The EEOC commissioners seem to understand this. They should be commended for their foresight, and their bureaucratic amendment to the EEOC's compliance manual (known charmingly as directives transmittal number 915.002) is one of the few such documents that deserves to be read.

Barbara J. Culliton 